ELORE (ISSN 1456-3010), vol. $16-1 / 2009$.

Julkaisija: Suomen Kansantietouden Tutkijain Seura ry.

[http://www.elore.fi/arkisto/1_09/ajank_saarikoski_01_09.pdf]

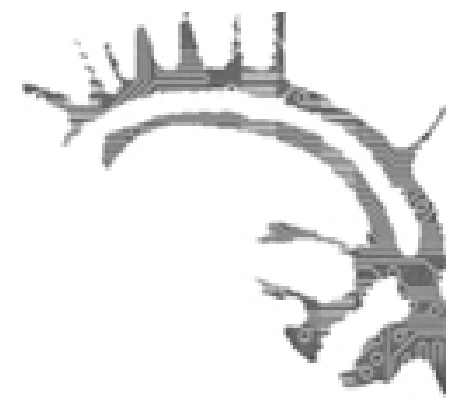

Ajankohtaista:

\title{
REILATEN KONGREsSiIN. MATKAKERTOMUS KesÄLtÄ 2008 IRLANTIIN
}

\section{$\underline{\text { Helena Saarikoski }}$}

Ilmastotalkoot edellyttävät kaikkien paria kolmea tuhatta kilometriä lyhyempien matkojen tekemistä maan pintaa pitkin. Käytännössä kaikki matkat Euroopan rajoissa menevät tähän mittaan. Matka viime kesänä Derryyn Pohjois-Irlantiin etnologi- ja folkloristikongressiin (ks. raportti, Koskinen-Koivisto ym. 2008) tarjosi hyvän tilaisuuden testata, vieläkö viimeksi kymmenen vuotta sitten koeteltu Interrail-kunto kestää. Lentomatka olisi vaatinut peräti kaksi välilaskua, lentomatkojen inhokkeja sekä ilmaston että matkailumukavuuden kannalta. En tiedä, onko kaikkein virallisin matkustusohjesääntö jo mukana ilmastotalkoissa. Kanslerin matka-avustuksen tilityksessä Interrail-kortti hyväksyttiin "reittilentoja olennaisesti edullisempana pakettimatkana". Menomatkan paikka- ja laivalippujenkin kanssa se todella tuli myös paljon halvemmaksi. Matkabudjetti ei levähtänyt sen pahemmin, kun laskutin kulukorvauksen vain kongressipäiviltä. Kongressin jälkeen matka jatkuikin pikemmin lomamatkana. Aikuisten Interrail-korteista valitsin vaihtoehdon, jossa on 22 voimassaolopäivää ja näistä kymmenen matkustuspäiviä. Matka kesti kolme vuorokautta Helsingistä Pohjois-Irlannin rajalle, johon Interrail-kortin kelpoisuusalue outoa kyllä päättyy, eli käytännössä laivalle Skotlannin Stranraerista Belfastiin. Loput matkustuspäivät käytin hieman viipyilevään kotimatkaan.

\section{Pohjois-IrLantiIn}

Matka alkoi tuttua reittiä Tukholman, Kööpenhaminan ja Hampurin kautta Hannoveriin, jossa pääsin yöjunaan ja sillä aamuksi Brysseliin. Tähän asti olin saanut junien paikkaliput varatuksi Helsingin asemalla. Jännitystä aiheutti aikomani yöjuna Lontoosta Glasgowhun: Scotrail ei antanut varata lippuja ulkomailta etukäteen, eikä matkustusyössä ollut valinnanvaraa, jos halusin pitää yhteyteni Belfastiin ja tulla ajoissa kongressiin. Menin brittien pääsaarelle laivalla perinteistä reittiä Calais’ta Doveriin. 


\section{ReILATEN KONGRESSIIN. MATKAKERTOMUS KESÄLtä 2008 IRLANTIIN}

Doverin aseman lippuluukulla pelko Skotlannin yöjunan suhteen näytti toteutuvan: makuupaikat olivat loppu ja jouduin varaamaan seuraavaksi yöksi istumapaikan junaan. Istuma-yön ajatteleminenkin tuntui siinä vaiheessa jo ylivoimaiselta. Selviydyttyäni junan lähtöasemalle Lontoon Eustoniin kävi ilmi sama kuin yleensä: loppuunmyytyyn junaan todennäköisesti saa ostaa vielä lippuja junan omalta henkilökunnalta, mutta se selviää vasta kun juna lastaa matkustajat, "on boarding".

Juna, Caledonian Sleeper, jatkui laiturilla silmänkantamattomiin. Useista vaunuista koostuvia osastoja merkittiin suurilla kirjaintauluilla, ja alkupään kohdalla minua neuvottiin johonkin kilometrien päähän, siltä tuntui, F-osaston junaemännän puheille. Hän oli hyvin tiukkana siitä, että joudun maksamaan hytistä täyden hinnan 36 puntaa (silloin 45 euroa), muttei puhettakaan, että tilaa ei olisi ollut. Sikäli kuin ymmärsin Scotrailin edustavan junaemännän murteesta yhtään mitään, onnella sen verran, että englannin murretta taisi olla. Sain loistolaatuisen hytin kokonaan itselleni ja heräsin hyvin nukutun yön jälkeen Glasgown asemalla, jonne juna oli tullut reippaasti etuajassa. Vielä muutaman tunnin matka paikallisjunalla Stranraeriin ja laivamatka Pohjanmeren ruotsalaisen varustamojätin Stena Linen kelvollisen siistillä lautalla, ja olen perillä Belfastissa.

\section{KYMMENEN VUOTTA JÄLKEEN RAUHANSOPIMUKSEN}

Sunnuntaiaamuna herään matkan rasituksista vähitellen siihen tietoisuuteen, etten ole nyt missä tahansa brittimaakunnan pääkaupungissa vaan uutisotsikoiden Belfastissa, Pohjois-Irlannin vuosikymmeniä jatkuneiden levottomuuksien, Troubles, päänäyttämöllä. Konferenssin aattopäivän ohjelmaan sopivasti uimahalli löytyy kartalta tutun kuuloiselta kadulta, the Falls Road, kuten sanotaan. Bussi jättää minut vastapäätä pientä pensasaidan kätkemää puistoa, joka osoittautuu Fallsin katolisen asuma-alueen taisteluissa kaatuneiden muistomerkiksi, Remembrance Garden. Pikku puistokäytävän varrella on vieri vieressä muistokiviä taisteluista 1920-luvulta 1990-luvun sotavankien nälkälakkouhreihin asti, kiveen hakattuine nimineen, ikineen, sotilas- tai siviiliarvoineen ja muistolauseineen, kuten sitaatti Padraig Pearsen kuuluisasta puheesta vuodelta 1915: "The fools! - they have left us our Fenian dead, and while Ireland holds these graves, Ireland unfree shall never be at peace."(1) Voi toivoa parempaa, tai olla eri mieltä, esimerkiksi siitäkin, onko "suurinta rakkautta" näännyttää itsensä nälkään isänmaan puolesta, mutta muistomerkin suorapuheisuus ei voi jättää liikuttamatta.

Sotilasarvot (upseereita tai vapaaehtoisia eli Irlannin tasavaltalaisarmeijan IRA:n(2) sotilaita tai sotavankeja, P.O.W.) eivät ole neutraaleja tiedonantoja vaan sotilaan statuksen vaatimuksia. Brittihallinto on aikoinaan ajanut rauhanpyrkimyksiä päättäväisesti samaan umpikujaan, johon Ranska ajoi Algeriassa ja johon Israel ajaa Gazassa tammikuussa 2009 tätä kirjoittaessani: vastapuolen kanssa kieltäydytään neuvottelemasta ja sotalakeja noudattamasta sillä perusteella, että "terroristien kanssa ei neuvotella" ja mitkään lait eivät suojaa "terroristeja". Rauhanneuvotteluista tuskin voi olla puhetta niin kauan kuin vastapuolelle ei myönnetä neuvotteluoikeuksia. 
Muistelen enkä muista, missä Suomessa olisi punaisten sotilaiden nimiä hakattuna kiveen tai missä Helsingissä on esimerkiksi Helsingin valtauksen museo. Kuka edes tietää mistä puhutaan, jos puhutaan "Kemin tapahtumista"? Yhteisön muistojen esille panemisen mahdollisuus täällä, ollaan kuitenkin yhä Ison-Britannian maaperällä, on mielestäni yhtäältä saman ongelmavyyhdin seurauksia. Väestöryhmien segregaation osana katolisten asuma-alueet ovat eristyneet osittain omalakisiksi getoiksi, mihin Derryssä 1960-luvun lopulla julistettu Bogsiden kaupunginosan vapaakaupunki Free Derrykin perustui. Toisaalta Iso-Britannia kaikkine kolonialismeineen ja riistokapitalismeineen on kuitenkin länsimaisen demokratian kehto nimenomaan suomalaisittain hämmästyttävän vapaan sanan mielessä. Suuriruhtinaskunnasta vasta kuoriutuneen valkoisen tasavallan politiikka kieltää toisen osapuolen kokemusten todellisuus ja uhrien rituaalinen muistaminen (Peltonen 1996) on näyttänyt yhdeksässäkymmenessä vuodessa seuraukset, joiden valossa brittien sietokyky ei ehkä, toivon mukaan, ole ollut hullumpaa.

Olen uimassa sunnuntaina kirkonmenojen aikaan, ja pikku virkistyshallissa on hyvin tilaa, vedessä leikkivien pikkulasten lauman, parin silloin tällöin arvokkaasti kroolikierroksen vetävän vanhemman miehen ja parin pituusennätyksiä sukeltelevan nuoren pojan joukossa. Monista eurooppalaisista uimaurheilupalatseista poiketen täällä on hyvät pesutilat, altaan kynnyssuihkuista erilliset peseytymissuihkut lämpimine vesineen, vieläpä pieni Tylo-saunakin. Varmaan samasta syystä kuin Helsinkiin aikoinaan rakennettiin yleisten saunojen ja uimahallin peseytymistilojen verkosto, paikkaamaan asuntojen kehnoa varustelua, mietin.

Kävellessäni Falls Roadia alaspäin takaisin kaupunkiin katsastan St. Peter's -kirkon ympäristössä kuuluisia seinämaalauksia, joista osa on kauhtuneita, mutta monet hyvässä maalissa pidettyjä. Pohjois-Irlannin kysymysten, IRA:n taistelun, sen uhrien ja historian ja kieli- ja kulttuuritaistelun lisäksi täällä julistetaan solidaarisuutta tasapuolisesti kaikkien kansojen vapaustaistelulle: baskeille, palestiinalaisille, latinalaisen Amerikan vallankumouksellisille ja monille muille.

Nähtävyyksien jälkeen mieleeni tulee jotain, mitä olen lukenut kongressipapereista: ei vain katsella, mitä näen täällä, vaan tunnustella, miltä täällä tuntuu. Tutkijan omista kokemuksista lähtevää etnografiaa kutsutaan kongressissa "uudeksi", vaikka refleksiivisyyden vaatimus ja autoetnografia ovat olleet etnografian suhteellista valtavirtaa parin vuosikymmenen verran.(3) Kuten Orvar Löfgren sanoi työryhmässämme(4), tutkijan omat kokemukset ovat ainoita kokemuksia, joihin meillä on pääsy. Ehkä yhä voimistunut ruumiillisuuden ja aistien todistuksen tutkimus on kypsyttänyt tiedon paikantuneisuutta ja tutkijan osallisuutta jo aikaa koskeneet metodologiset asettamukset "uudeksi" ruumiillisen kokemuksen etnografiaksi.

Mikä siis on tutkijan henkilökohtainen kokemus Falls Roadilla? Heti ajatuksen tultua tunnen yhtäkkiä, kuinka raskaat kantamukset minulla on. Vaikka kassissa on mieluisia tuliaisia, kirjoja ja muita ostoksia Fallsin kulttuurikeskuksesta, enhän kestä raahata tällaista taakkaa! Tunnelma on äkkiä kova, katkera, raskas. Ruumiillinen raskauden kokemus on varma, itsessään luotettava, lähes vastaansanomaton. Mutta miten se voisi olla etnografin siirtokelpoista tietoa, tutkijan havainto? Kaikesta ruumiillisuuden ja aistimuksellisuuden korostuksesta huolimatta päädyn panemaan toivoni sanallisen 


\section{Reilaten Kongressiin. MatKakertomus kesältä 2008 Irlantiln}

kertomuksen kykyyn välittää kokemuksen laatua toisille ihmisille. Falls Road on kova katu, eikä kovuus ole sen nähtävyyksissä, vaan sen tunnussa, paikan hengessä ja historiassa, ihmisten kertomuksissa.

\section{VERISUNNUNTAIN MUISTO}

Pohjoisirlantilainen muraaliperinne on noin satavuotias tapa julistaa historian tapahtumia oman osapuolen näkökulmasta, mutta tasavaltalaisten julistuskeino siitä on tullut vasta vuoden 1981 sotavankien nälkälakkoprotestien aikaan (Rolston 1998, i). Katolisten muraaliperinne, joka Belfastissa näytti kansanomaisen rönsyilevältä, on Derryssä institutioitu järjestäytyneen taiteilijakollektiivin luomaksi ja turistiviranomaisten suosittelemaksi nähtävyydeksi. Free Derry Corner, vuoden 1972 verisunnuntain tapahtumapaikka ja siihen keskittyvän museon Museum of Free Derryn ympäristö, kertoo tyylikkäin ja militantein maalauksin kaikkialla talonseinillä kansalaisoikeustaistelun tapahtumista paikalla (Bogside Artists > Murals). Näitä seiniä on alettu maalata 1994, samana vuonna kuin IRA julisti rauhanprosessiin johtaneen tulitaukonsa. Aktiivisen taistelun taukoaminen on mahdollistanut sen kuvakertomukseksi etäännyttämisen ja esillepanon ritualisoidussa muodossa.(5)

Bloody Sunday, kansalaisoikeusmarssi, jossa brittisotilaat ampuivat kuoliaaksi neljätoista aseetonta mielenosoittajaa ja jota pidetään Troublesin varsinaisena lähtölaukauksena, on voitu panna esille hyvin tarkasti syystä, joka minua etnografina järkytti tässä museossa kaikkein eniten. Ennen verisunnuntaita Derry oli ollut usean vuoden ajan kansalaisoikeusliikkeen kärkitanner ja postkoloniaalisen taistelun näyteikkuna Euroopassa.(6) Paikalla oli siksi suuri joukko erimaalaisia toimittajia, jotka dokumentoivat verilöylyn joka sekunnin runsain kuva- ja äänitallentein. Lyhyen Derryn yleisen historiaosan jälkeen museossa kiertävä tulee tietokonepäätteille, joilla voi kuunnella toimittajien verisunnuntain mielenosoituksessa äänittämiä nauhoja ja kelata kuvia. Ihmiset ensin laulavat We shall overcome..., kuuluu laukauksia, hämmästynyt miehen ääni huudahtaa "Fascists?", sitten alkaa huuto. Paikallinen tieto, jota museo haluaa esitellä uhreista, jotta he eivät olisi vain jokavuotisella muistomarssilla kannettavia kuvia ja ristejä, onnistuu lähentämään tapahtuman. Tavallisista museoista poiketen muistoesineitä ei ole Vapaan Derryn museossa monta, mutta muun dokumentaation osana läpiammuttu miehen paita tai tapetun kuvaajan kamera todella puhuttelevat katsojaa. Verisunnuntain oikeudellinen selvitys on edelleen 37 vuoden jälkeen kesken, ampujat tiedetään, mutta he eivät ole joutuneet vastaamaan teoistaan vaan päinvastoin ylenneet asianmukaisesti brittiarmeijan virkaportailla. Museoltakaan ei sovi odottaa draamaa seuraavan uteliaan turistin katharttista vapauttamista. Vapaan Derryn museo on ottanut tehtäväkseen pitää uhrien muistoa yllä ja oikeuden asiaa vireillä. Vastaavaa virallisen totuuden ja hallitsevan vallan haastavaa näkökulmamuseota en muista toista tavanneeni.

Kesällä 2008 rauhansopimuksesta oli kulunut kymmenen vuotta. Kävellessämme jonakin kongressipäivänä Ulsterin yliopiston Mageen kampukselta keskustaan Guildhallille iltaistuntoon juttelin australialaisen Pohjois-Irlantiin asettuneen näyttelijä- 
ohjaajan Matthew Jenningsin kanssa, joka oli kongressissa kertomassa tekemästään yhteisöteatterityöstä (SIEF:n kongressikäsikirja, 52). Yhteisöteatteri on yksi monista työmuodoista, joilla Troublesin traumoja on työstetty ja käsitelty. Työ on ollut pitkälti kansalaisjärjestöjen harteilla ja sitä on näihin asti rahoitettu avokätisesti osana rauhanprosessia muun muassa eurooppalaisista lähteistä. Matthewn kertoman mukaan tilanne on nyt muuttunut: rahoittajat ovat sitä mieltä, että kymmenen vuotta rauhaa riittää, nyt on palattu normaalitilaan kuin mitään Troublesia ei olisi koskaan ollutkaan, ja kymmenet kansalaisjärjestöt ovat joutuneet lyömään lapun rauhanprosessityön luukulle. Samaan aikaan konfliktin syihin ei ole juuri pystytty vaikuttamaan, jos on yritettykään; sosiaalinen eriarvoisuus ja segregaatio eivät ole ainakaan vähentyneet kuluneiden vuosien aikana. Ennuste on pessimistinen: niin kauan kuin aktiivi-iässä ovat sukupolvet, jotka ovat täysin kyllästyneitä kaikkeen tappelemiseen, rauha on hyvä vaihtoehto, mutta jos tappelemisen syyt pysyvät eikä ole parempaakaan tehtävissä, aseeseen tarttumisen vuosisatainen perinne on kyllä kaikilla osapuolilla muistissa.

Derryn työväenluokkaisista protestanttinuorista 1980-luvulla kenttätutkimuksen tehneen sosiologin Desmond Bellin mukaan Pohjois-Irlannissa ei ole kyse sosiaalisesta ongelmasta, jonka juuret olisivat irlantilaisessa kulttuurissa, vaan ratkaisemattomasta postkoloniaalisesta tilanteesta, poliittisesta ongelmasta (Bell 1990; teoksesta ks. myös Saarikoski 1991). Irlantilaisilla on oma jäljittelemättömän pateettinen tyylinsä panna ongelma esille, mutta pohjimmiltaan sama tapahtuu uudestaan kaikkialla, missä taistellaan itsemääräämisoikeudesta ja yhteiskunnallisesta oikeudenmukaisuudesta. Siksi Fallsin Remembrance Garden ja Bogsiden Museum of Free Derry eivät ole vain paikallisyhteisöjen ja yksittäisten ihmisten muistojen paikkoja. Kun erityinen on tarpeeksi läheistä ja yksityistä, jonkun omaa, siinä on samalla yleinen ja yhtäläinen.

\section{ETELÄ-IRLANNIN TURISTIKEIDAS}

Irlanti ei ole paras mahdollinen maa reilaajan kannalta: poikittaisratoja ei ole juuri lainkaan, vaan Dublinista lähtee kolme päärataa, pohjoiseen Belfastiin, länteen Galwayhin ja etelään Corkiin, joiden välillä matkailijan on miltei valittava kohteensa. Radalta toiselle vaihtaminen edellyttää aina matkaa Dublinin kautta, tai sitten bussia, jos sellainen poikittaisreittejä kulkee. Irlanti on vielä napoleonisempi kuin Ranska siinä, missä määrin kaikki rautatiet vievät vain valtakunnan keskustaan. Suuntasin eteläistä rataa sen päätepisteeseen Tralee'hin, josta jatkoin vielä bussilla pieneen Dinglen kaupunkiin Irlannin lounaiskärjessä Dingle Bayn rannalla. Olisi voinut kuvitella olevansa jossakin Nauvossa parhaaseen sesonkiaikaan. Itse kaupunki on pienempi kuin sen kalastus- ja huvivenesatamat, mutta asukas- ja kävijämäärä varmaan satakertainen talvikauden kahteentuhanteen asukkaaseen verrattuna. Elinkeinoissa on postmodernia teollisuuden jälkeisen ajan potpuria: turismi, kalastus ja maanviljely, tässä järjestyksessä.

Toisaalta juuri maaseudun, kuten vanhastaan kalastuksella elävän rannikon, turistirysien katsastamiseen Interrail-matkailu on onnen omiaan. Eiväthän turistirysät suinkaan turhaan ole suosittuja matkakohteita, mutta mitä muuta voi nähdä 


\section{ReILATEN KONGRESSIIN. MATKAKERTOMUS KESÄLtä 2008 IRLANTIIN}

kuin turisteja ja kokea kuin turismia, on toinen juttu. Paikallisjunilla liikkuu samassa tavallisten ihmisten kanssa eikä turistien ruuhkauttamilla autoteillä; halvoissa hostelleissa pääsee ihmisten kanssa puheisiin; voi ostaa lampaankyljyksiä Butcher'silta ja paistaa niitä itselleen hostellin yhteiskeittiössä, ruokapöydän keskustelukumppanit voivat yllättää. Voi löytää ilmoitustaululta tapahtumia, joita turistioppaissa ei mainita, kuten Dinglessä löysin paikallisen musiikkikoulun rumpukurssin ja sain oppia alkeet irlantilaisen kehärummun soitto-otteesta (ehkä enempää ei uskalla väittää oppineensa, muutamaa uutta rumpalivitsiä lukuun ottamatta). Sikäläinen retkeilymaja, Youth Hostel, on entinen maatalo, jota sen omistajat pitävät nyt majatalona. Rahalla saa varmaan mukavampaa, työläästä ja likaisestakin paikallisesta todellisuudesta irrallista matkailua, mutta Visa-kortilla ei aina pääse, mihin IR- ja YH-korteilla pääsee.

Hitaammin matkustaen pääsee lähemmäksi paikkoja. Se tuntuu etnologiatieteiden kongressille sopivammalta lähestymistavalta kuin paikaton kongressiturismi, jossa kongressit voitaisiin oikeastaan helpommin pitää kansainvälisillä lentokentillä kuin turhaan vaivautua kaupunkeihin. SIEF:n kongressi oli suurin Mageen kampuksella tähän asti järjestetty kansainvälinen kokous. Kongressilla oli merkitystä paikalle. Paikalla soisi olevan merkitystä myös kongressiväelle.

\section{VIITTEET}

1. Seppo Loposen suomennoksena (Devlin 1971, 57): "Voi niitä hölmöjä! Jättivät meille feeniläisvainaamme! Niin kauan kuin Irlannilla on nämä haudat, ei kahlittu Irlanti lepää." Pearsen puhetta pidetään Irlannin itsenäisyystaistelun merkkitapauksen, vuoden 1916 Pääsiäiskapinan, yhtenä lähtölaukauksena. Viimeinen lause Ireland unfree shall never be at peace on irronnut puheesta nationalistien iskulauseeksi.

2. IRA, lyhenne sanoista Irish Republican Army. Eri aikoina eri fraktiot ovat johtaneet itsenäisyystaistelua, Troublesin aikana lähinnä niin sanottu väliaikaissiipi PIRA (Provisional IR A). Perinnetietoa IRA:n historiasta, ks. esim. englanninkielinen Wikipedia, List of IRAs.

3. Dialogisen antropologian metodologisena vaatimuksena on etnografian refleksiivisyys, jonka avulla tutkija asemoituu tutkimuskohteen tai -aineiston kanssa käytävän dialogin toiseksi osapuoleksi, positivistisen "objektiivisuuden" edellyttämän ulkopuolisen auktoritatiivisen monologin sijasta (kirjallisuutta ks. Saarikoski tulossa 2009).

4. Orvar Löfgrenin ja Billy Ehnin johtama työryhmä "Imagination at Work: Daydreaming and Fantasizing in Everyday Life", ks. SIEF:n 9. kongressin käsikirja, 37-38.

5. Derryn muraalien tekijäkollektiivi Bogside Artists kertoo internetsivuillaan tästä historian näyttämisen periaatteesta.

6. Hyvä, tiivis johdatus pohjoisirlantilaisen kansalaisoikeustaistelun ja yleisemminkin Irlannin historiaan tasavaltalaisosapuolen näkökulmasta on nuoren Bernadette Devlinin (nyk. McAliskey) vuonna 1969 julkaistu, tuoreeltaan suomennettu muistelmateos (Devlin 1971). 


\section{LÄHTEET JA KIRJALLISUUS}

$B B C$ News Online's in-depth guide to the causes of the conflict in Northern Ireland [online]. < http://news.bbc.co.uk/hi/english/static/northern_ireland/understanding/ > [1.1.2009.]

BELL, DESMOND 1990: Acts of Union. Youth Culture and Sectarianism in Northern Ireland. Hampshire: Macmillan.

Bogside Artists [online]. < http://cain.ulst.ac.uk/bogsideartists/menu.htm > [31.12.2008.]

DEVLIN, BERNADETTE 1971: Sieluni binta. Helsinki: Tammi. Alkuteos The Price of My Soul 1969, suomentanut Seppo Loponen.

Falls Roadin muraaleja [online]. < http://www.gransha-taxi.co.uk/Belfast_murals_ Falls_road.htm $>$ [31.12.2008.]

KOSKINEN-KOIVISTO, EERIKA, NISKANEN, HELI JA TURUNEN ARJA 2008: Kulttuuriperintöä Derryssä. Elore 15 (2) [online]. < http://www.elore.fi/ arkisto/2_08/knt2_08.pdf $>$ [27.12.2008.]

Museum of Free Derry [online]. < http:/ / www.museumoffreederry.org/ > [31.12.2008.]

PELTONEN, ULLA-MAIJA 1996: Punakapinan muistot. Tutkimus työväen muistelukerronnan muotoutumisesta vuoden 1918 jälkeen. Helsinki: SKS.

ROLSTON, BILL 1998: Drawing Support 2: Murals of War and Peace. Belfast: Beyond the Pale.

SAARIKOSKI, HELENA 1991: Etnisyyden tuottaminen nuorisokulttuurissa. [Arvio teoksesta Bell 1990.] Nuorisotutkimus 9 (3), 41-43.

SAARIKOSKI, HELENA (TULOSSA 2009): Nuoren naisellisunden koreografioita. Spice Girlsin fanit tyttöyden tekijöinä. Helsinki: SKS [painossa].

SIEF:n (Société Internationale d'Ethnologie et de Folklore) 9. kongressin käsikirja [online]. < http://www.arts.ulster.ac.uk/sief2008/docs/SIEF_handbookcontent.pdf > [31.12.2008.]

Wikipedia, List of IRAs [online]. < http://en.wikipedia.org/wiki/List_of_IRAs > [18.1.2009.]

Filosofian tohtori Helena Saarikoski on folkloristiikan dosentti Helsingin yliopistossa ja toimii naistutkimuksen erikoistutkijana Turun yliopistossa. 